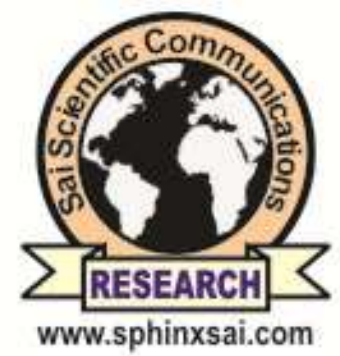
International Journal of PharmTech Research
CODEN (USA): IJPRIF, ISSN: 0974-4304, ISSN(Online): 2455-9563

Vol.13, No.04, pp 388-392,

2020

\title{
Clinico-Epidemiological Features of Melasma : A Retrospective Study from Dermatology-Venereology Department of Education Center Hospital in West Sumatera, Indonesia
}

\author{
Satya Wydya Yenny \\ ${ }^{1}$ Dermatology and Venereology Department of Dr.M.Djamil General Hospital \\ Medical Faculty of Andalas University. Padang/Indonesia Telephone : 08126617869.
}

\begin{abstract}
Background: Melasma is an acquired, irregularly patterned, light to dark-brown hypermelanosis, with symmetric distribution mostly over the face. Currently there is no published data about incidence of melasma in Indonesia. Methods: Retrospective study was conducted in patients with melasma from January 1, 2016 to December 31, 2018 in Dr. M. Djamil hospital padang, Indonesia. Results: Melasma was more prevalent in females (96.6\%) and in Fitzpatrick skin phototypes IV (60\%) and III (40 \%). Among 60 patients, centrofacialmelasma was most common (48.3\%), Family history (58.1\%) and sun exposure exceeding 1 hour $(61.3 \%)$ were among the factors contributing to melasma development. The incidences of melasma in 2016-2018 varied every year, the most affected was in female 44-64 years old, the most clinical type is Centrofacial, and epidermal type from Wood's lamp examination. Conclusions: This population was characterized by: a high incidence in females, Fitzpatrick skin phototypes IV, diseasepresipitation by family history and sun exposure.
\end{abstract}

Keywords : Features, Indonesia, Melasma, West sumatera.

\section{Introduction}

Melasma is one of the most commonly acquired hyperpigmentations that mainly affects the face. ${ }^{1}$ The disorder can affect men and women of all ethnicities and skin types but more prevalent in women with Fitzpatrick skin types III to $\mathrm{V}$ who are exposed to ultraviolet (UV). ${ }^{2,3}$ The prevalence of melasma varies between $1.5 \%$ and $33.3 \%$ depending on the population. ${ }^{4}$ The incidence of melasma is estimated to occur in $15-$ $35 \%$ of adult Brazilian women. In Iran, melasma was identified in $39.5 \%$ of women, $9.5 \%$ of which were pregnant women. In the United States, melasma affects five to six million people. ${ }^{5}$ Salim YF, Yenny SW and Lestari S (Padang,2016) reported the incidence of melasma in Dermatology Department Outpatient of Dr.M.Djamil Hospital Padang in 2012-2015 was 0,61 \%. Melasma is more prevalent in women, in an estimated 9:1 ratio compared to men. In Southeast Asia, for example, the prevalence reaches $40 \%$ in adult women and 20 $\%$ in adult men. In Puerto Rico, men formed only $10 \%$ of the total melasma patients. In India, 20-25\% of patients with melasma are men. ${ }^{5}$

Satya Wydya Yenny /International Journal of PharmTech Research, 2020,13(4): 388-392.

DOI: http://dx.doi.org/10.20902/IJPTR.2019.130411 
The exact causes of melasma are unkown. The most commonly reported precipitating factors are pregnancy, oral contraceptives, and sun exposure. ${ }^{3,6}$, The family history of melasma occurs in about $50 \%$ of patients, particularly in those with darker skin types. Its prevalence in pregnancy is around $50-70 \%$. These rates suggest a hereditary etiological component which is being considered the most important risk factor for melasma development. ${ }^{5}$

Three clinical patterns are usually described: centrofacial, with patches on the frontal region, nasal dorsum, cheekbones, and chin areas (65\% of the cases); malar, which occurs in $20 \%$ of the cases; and mandibular, seen in about $15 \%$ of the patients.

Using the Wood's light examination, melasma can be classified into four major histological types depending upon the depth of pigment deposition. The epidermal type, dermal type, mixed type and intermediate type. ${ }^{7}$ This study is aimed at studying the epidemiology, clinical presentation, and precipitating and/or provocation factors associated with melasma.

\section{Methods}

This was a retrospective study of melasmain Dr. M. Djamil General Hospital Padang, Indonesia, between January 1, 2016 and December 31, 2018. Data of patients who diagnosed as Melasma were obtained from medical records, including demographic information (age, sex), duration of disease, Fitzpatrick skin types, family history, precipitating factors, type of melasma and clinical presentation of melasma.

\section{Results}

Sixty patients with melasma were included in this study; their main characteristic information are presented in table 1 , which represents $0.10 \%$ of the total 560 new cases in outpatient department of dermatology. It was more common in women, with a female to male ratio of 29: 1 . There were 58 patients (96.6\%) females and $2(3.3 \%)$ males, with age range of 15 to 64 years. There were $43.3 \%$ in the age group between 44 and $<64$ years, $41.7 \%$ in the age group between 24 and $<44$ years, $8.3 \%$ in the age group between $15-<24$ years and $6.7 \%$ in the group $\geq 64$ years. A positive family history was obtained from $65 \%$ of the melasma patients (Table 1). Out of 60 patients, $36(60 \%)$ patients had type IV of Fitzpatrick skin types and the remaining $24(40 \%)$ patients had type III Fitzpatrick skin types.

Table 1. Characteristic of Melasma Patients in Dermatology-Veneorology Outpatient Clinic of Dr. M. Djamil Hospital Padang during January 2016 - December 2018

\begin{tabular}{|c|c|c|}
\hline $\begin{array}{c}\text { Epidemiology and clinical } \\
\text { profile }\end{array}$ & $\begin{array}{c}\text { Case number } \\
(\mathbf{n = 6 0 )}\end{array}$ & $\begin{array}{c}\text { Percentage } \\
\text { Total Cases } \\
(\boldsymbol{\%})\end{array}$ \\
\hline Sex & & \\
\hline Male & 2 & $3,3 \%$ \\
\hline Female & 58 & $96,6 \%$ \\
\hline Age (Year) & 5 & $8,3 \%$ \\
\hline $15-<24$ & 25 & $41,7 \%$ \\
\hline $24-<44$ & 26 & $43,3 \%$ \\
\hline $44-<64$ & 4 & $6,7 \%$ \\
\hline$\geq 64$ & & \\
\hline Duration of Disease (Year) & 0 & \\
\hline$<2$ & 1 & $0 \%$ \\
\hline$\geq 2$ & & $0 \%$ \\
\hline Fitzpatrick phototype & 0 & $40 \%$ \\
\hline I & 0 & $60 \%$ \\
\hline II & 24 & \\
\hline III & 36 & \\
\hline IV & & \\
\hline
\end{tabular}




\begin{tabular}{|c|c|c|}
\hline V & 0 & $0 \%$ \\
\hline VI & 0 & $0 \%$ \\
\hline Family History & & \\
\hline Yes & 39 & $65 \%$ \\
\hline No & 21 & $35 \%$ \\
\hline
\end{tabular}

Table 2. Main Clinical patient data

\begin{tabular}{|l|l|l|l|}
\hline \multicolumn{2}{|l|}{} & $\mathbf{n}$ & $\begin{array}{l}\text { Percentage } \\
(\mathbf{\%})\end{array}$ \\
\hline \multirow{4}{*}{$\begin{array}{l}\text { Precipitating } \\
\text { factors }\end{array}$} & UV Radiation & 20 & $33,3 \%$ \\
\cline { 2 - 4 } & Contraseptive & 11 & $18,8 \%$ \\
\cline { 2 - 4 } & Cosmetics & 6 & $10 \%$ \\
\cline { 2 - 4 } & Drugs & 0 & 0 \\
\cline { 2 - 4 } & Pregnancy & 7 & $11.7 \%$ \\
\cline { 2 - 4 } & Genetics & 0 & 0 \\
\cline { 2 - 4 } & Idiopatics & 0 & 0 \\
\hline \multirow{3}{*}{$\begin{array}{l}\text { Distribution } \\
\text { of melasma }\end{array}$} & Malar & 26 & $8.3 \%$ \\
\cline { 2 - 4 } & Centrofacial & 29 & $48.3 \%$ \\
\cline { 2 - 4 } & Mandibular & 5 & $8.3 \%$ \\
\hline \multirow{3}{*}{$\begin{array}{l}\text { Type of } \\
\text { melasma }\end{array}$} & Epidermal & 20 & $33.3 \%$ \\
\cline { 2 - 4 } & Dermal & 17 & $28.3 \%$ \\
\cline { 2 - 4 } & Mixed & 23 & $38.3 \%$ \\
\hline
\end{tabular}

The major precipitating factors identified were UV radiation (33.3\%), followed by cosmetics (10\%), contraceptive $(18.8 \%)$, and pregnancy $(11.7 \%)$. According to the distribution of lesions, three clinical patterns of melasma were observed and among these, the centrofacial type was the most common; seen in 29 (48.3\%) cases. Other types noted were malar $26(43.3 \%)$ and mandibular 5 (8.3\%), respectively. Under the Wood's light examination Mixed was the most common pattern seen in $23(38.3 \%)$ patients; and in $20(33.3 \%)$ and 17 $(28.3 \%)$ cases, the patterns were epidermal and dermal type, respectively.

\section{Discussion}

Melasma is a common dyschromia that often motivates the search for dermatological care. Its prevalence varies according to ethnic composition, skin phototype, and intensity of sun exposure. Melasma prevalence study was varied. Walker et.al.in Nepal showed that melasma was the most commonly reported pigmentary dermatosis. ${ }^{8}$ Umborowati (Surabaya,2014) reported there was $14.1 \%$ melasma patients among new patients in Medical Cosmetic Division in outpatient Clinic Dr.Soetomo General Hospital Surabaya. ${ }^{9}$ Salim YF (Padang,2018) reported 0, 61\% incidence of melasma in Dr.MDjamil Hospital Padang since 2012-2015. ${ }^{10}$ The most cases in this study was found in age group 44-<64 years old. Salim YF (Padang,2018) reported the most cases of melasma was found in 25-44 years old at Outpatient Clinic of Dermato-Venereology in Dr.MDjamil Hospital Padang since 2012-2015. This study showed that melasma is most commonly in women (96.6\%) then men. It is similar with study conducted by Asditya A and Sukanto H (Surabaya,2017) which said women predominance in melasma $(98,6 \%) .{ }^{11} \mathrm{Haxel}$ et al. (Brazil, 2013) said women are more prone to develop this condition (97.5\%). ${ }^{12}$ In a 2013 population-based study involving 515 adult employees of the University Campus of Botucatu, Sao Paulo State University, Brazil, melasma was identified in 34\% of women and 6\% in men. A clear predominance was observed in the reports of the disease, ranging from 9 or 10 to 1 (estimate range). An Indian study found a less significant prevalence (6:1), whereas in Brazil and Singapore, there was also a clear female predominant: $39: 1$ and $21: 1$, respectively. ${ }^{12,13}$

This study showed skin phototypes of melasma patients, skin phototypes III (40 \%) and IV (60\%). Hexsel et al ( Brazil, 2013) was reported prevalence of melasma was higher in skin phototypes III (36.3\%) and IV (39.7\%). ${ }^{12}$ Pawar et al ( India, 2015) was reported $83.33 \%$ had type IV, $10 \%$ had type V and $6.67 \%$ patients had type III Fitzpatrick skin types, ${ }^{7}$ and in Tunisian study $14 \%$ presented with phototype III, $45 \%$ phototype IV 
and $41 \%$ phototype V. ${ }^{7}$ Demirkan et al ( Turkey,2017) showed of the 263 patients with melasma, the Fitzpatrick skin type 3 was seen in $79(30 \%)$ patients but the majority had the skin type 4, $184(70 \%)$ patients. ${ }^{14}$ Since melasma results from a local change in pigmentation, it preferably affects more strongly melanized phenotypes, and is mainly present in intermediate skin types III-V (Fitzpatrick classification), but rare in extreme skin types. In a sample of 302 Brazilian patients, 34.4\% had skin type III, 38.4\% had skin type IV and $15.6 \%$ had skin type V. In Tunisia, a survey of 188 women showed that: $14 \%$ had skin type III, $45 \%$ had skin type IV and $40 \%$ had skin type V. Similarly, a multicenter study involving 953 patients from three different Brazilian regions, identified that $13 \%$ had skin type II, $36 \%$ had skin type III, $40 \%$ had skin type IV and $10 \%$ had skin type V. It is theorized that individuals with skin type I fail to produce additional pigmentation, and individ- uals with skin type VI already produce it at maximum efficiency. Thus, skin types I and VI characterize phe- notypes of stable pigmentation. This is also evidenced by the small number of cases of melasma among the European population (with predominantly low skin types) and sub-Saharan Negroid peoples. ${ }^{15}$

Exposure to UV light is the most common etiologic factor. In our study, sun exposure was a strong aggravating factor in patients, that is, $33.3 \%$ of the patients reported a history of sun exposure. Similarly, Pathak had also reported sun exposure as a trigger factor in all patients in his study. UV radiation directly induces the increase of melanogenic activity, causing the development of epidermal pigmentation and occurring more intensely in regions with melas- ma than in the adjacent skin. The prevalence of melasma during pregnancy varies greatly among the different countries studied. A cross-sectional study in Southern Brazil identified melasma in $10.7 \%$ of 224 pregnant women. In Iran, melasma was identified in $16 \%$ of women; in Morocco, in 37\%; and in Pakistan, in 46\%. This strengthens the evidence of hormonal involvement in the genesis of the disease, since high levels of estrogen, progesterone and melanocortin are possible triggering factors of melasma during pregnancy.

In this study, centrofacial type was the most common; seen in $29(48.3 \%)$ cases. Other types presented with malar melasma, 26 (43.3\%) and mandibular 5 (8.3\%). Salim YF (Padang,2018) reported the most common type of melasma was malar type. ${ }^{10}$ Similarly with Guinotet al. (Tunisian,2010) found $76 \%$ of the patients presented with centrofacialmelasma, while only $23 \%$ presented malar and $1 \%$ mandibular melasma. ${ }^{16}$ Dharniet.al (India, 2018) was observed that out of the 80 patients, $38(47.5 \%)$ patients had centrofacial pattern, $31(38.75 \%)$ patients had malar pattern, and $11(13.75 \%)$ patients had mandibular pattern. ${ }^{17}$ Suryanigsih (Indonesian, 2018) was reported the centrofacial type of melasma is most common $(65 \%){ }^{18}$

Under Woods lamp examination we observed mixed pattern is more common, 23 (38.3\%) patients; and in $20(33.3 \%)$ and $17(28.3 \%)$ cases, the patterns were epidermal and dermal type. In contrast to Pawar S (India, 2015) was presented epidermal pattern is commonest. ${ }^{7}$ Achar study, and similar to Nicolaidou study which suggested that epidermal variety is most common. Shah et al, in their study observed $58.3 \%$ cases of epidermal melasma and $41.7 \%$ cases of dermal melasma. On contrary, another study reported epidermal pigment in 36\% cases, dermal pigment in $46 \%$ cases and mixed pigment in $18 \%$ cases. Assessing pigment level also helps in deciding the prognosis of melasma for example in case of dermal melasma, prognosis is not so good and treatment will be required for longer duration. ${ }^{19}$

\section{Acknowledgements}

none

\section{Declarations}

Funding: No funding sources

Conflict of interest: None declared 


\section{References}

1. Lapeere h, al e. Hypomelanosis and hypermelanosis. In: fitzspatrick's dermatology in general medicine. 8th ed. New york; 2012. P. 819.

2. Jiang j, akinseye o, pandya ag. International journal of women' $s$ dermatology the effect of melasma on self-esteem : a pilot study 弥, 论弥. Int j women's dermatology [internet]. 2018;4(1):38-42.

3. Lee ay. An updated review of melasma pathogenesis. Dermatologica sin [internet]. 2014;32(4):233-9.

4. Young kang h, ortonne jp. Melasma update. Actas dermosifiliogr. 2009;100(suppl. 2):110-3.

5. Cestari t, peruzzo j, giongo, natalia. Definition, incidence, and etiology of melasma in brown skin. In: handog eb, enriquez-macarayo mj, editors. Melasma and vitiligo in brown skin. 1st ed. India; 2017. P. 13-9.

6. Sonthalia s, sarkar r. Etiopathogenesis of melasma. Pigment int. 2015;2(1):21.

7. Khatu ss, hospital g. A clinico-epidemiological study of melasma in pune patients journal of pigmentary disorders a clinico-epidemiological study of melasma in pune patients. 2016;(october).

8. Jagannathan $\mathrm{m}$, sadagopan $\mathrm{k}$, ekkarakudy $\mathrm{j}$, anandan $\mathrm{h}$. Clinico-epidemiological study of patients with melasma in a tertiary care hospital - a prospective. Int j sci c study. 2017;4(11):117-20.

9. Umborowati ma. Studi retrospektif: diagnosis dan terapi pasien melasma ( retrospective study: diagnosis and therapy of melasma patients ). 2011;56-63.

10. Djamil rm, tahun p. Insidens melasma di poliklinik kulit dan kelamin laporan kasus. 2018;7(supplement 2):71-3.

11. Asditya a, sukanto h, staf d, fungsional $\mathrm{m}$, kesehatan i, kedokteran $\mathrm{f}$, et al. Studi retrospektif : profil pasien melasma ( profile of melasma patients : a retrospective study ). Berk ilmu kesehat kulit dan kelamin - period dermatology venereol. 2017;29/no.3/ d.

12. Weber mb, kalil clp v., lacerda da, cavalcante as, azulay-abulafia 1, lopes nfp, et al. Epidemiology of melasma in brazilian patients: a multicenter study. Int j dermatol. 2013;53(4):440-4.

13. Goh c, dlova c. A retrospective study on the clinical presentation and treatment outcome of melasma in a tertiary dermatological referral centre in singapore.

14. Demirkan s, gündüz ö, sayan cd. Retrospective analysis of endemic melasma patients. 2017;9:31-3.

15. Handel ac, miot ldb, miot ha. Melasma: a clinical and epidemiological review. An bras dermatol. 2014;89(5):771-82.

16. Guinot c, cheffai s, latreille j, dhaoui ma, youssef s, jaber k, et al. Aggravating factors for melasma : a prospective study in 197 tunisian patients. 2010;1060-9.

17. Article o. Correlation of clinicodermatoscopic and wood's lamp findings in patients having melasma. 2019;91-5.

18. Suryanigsih be. Characteristics of facial melasma on javanese women in yogyakarta , indonesia. 2018;28(may 2016):306-10.

19. Sharma m,et.al. A clinico-dermatoscopic study of 100 cases of melasma in a tertiary care hospital. Int $\mathrm{j}$ res dermatology. 2018;4(1):41. 